\title{
Development of electric facilities dispatching system of metallurgical enterprise
}

\author{
Svetlana Fedorova ${ }^{1, *}$, Pavel Khudyakov ${ }^{1}$, and David Tomilin ${ }^{1}$ \\ ${ }^{1}$ Ural Mining and Metallurgical Company Technical University, 3, pr-t Uspensky, Verkhnyaya \\ Pyshma Sverdlovsk region, 62409, Russia
}

\begin{abstract}
The creation of electrical facility modern dispatching system in an industrial enterprise should be part of the overall digitalization strategy, ensuring reliable and safe operation of electrical installations, which in turn will have positive impact on the competitiveness of industrial enterprise. The article describes the principles and algorithms for constructing of electrical facility monitoring and control system on the example of metallurgical enterprise. It is described the pilot project of the plant's electrical facilities dispatching control implementation, defining ecological safety. One of the significant results of the dispatch system introduction for the sulfuric acid subdivision is to reduce technological equipment downtime by $30 \%$. The stages and tools for improving the operational and dispatch management of the enterprise's electrical facilities are developed. The developed system of the company's electric facilities dispatching, combining information channels with three major downgrade substations, will allow solving the problems of electrical parameters, monitoring of the substation equipment state, and controlling the load of transformers, switching equipment. In addition, it becomes possible to control the specific electricity consumption of the main process equipment and efficiently to plan electricity when working in the wholesale market, as well as to increase the speed of decisionmaking to eliminate and prevent unwanted operating modes.
\end{abstract}

\section{Introduction}

Numerous scientific papers are devoted to the issue of development of a dispatching control system for the electric power facilities (DSC) on industrial enterprises. [1-3]

Main goal of all these papers is achieving reliable, safe and efficient electric power facilities due to possibilities of DSC.

The most important stage in the development of DSC is introducing of an automated dispatch control system (ADCS) and its integration with other automated systems of the enterprise (APCS, ASUM, ASTPM, ASPM ), which leads to creation of a modern digital enterprise. [4-6]

The issue is profoundly revealed in researches dedicated to large energy systems (districts, cities). [7-10]

Presently, the electrical facilities of industrial enterprises also represent power systems.

\footnotetext{
* Corresponding author: s.fedorova@ugmk.com
} 
Therefore, it is necessary to take into account the successful practices of organizing of the ODC at the level of energy system and to develop approaches to improving the ODC at the level of electric power facilities of industrial enterprises in order to ensure their reliable and safe operation.

Analysis of the experience of introduction of dispatching systems at industrial enterprises by world famous companies such as Siemens, Schneider Electric and ABB has shown that these complex solutions covering all the enterprise management systems, including the electrical system as one of the subsystems. [11-13]

Firstly, such projects are expedient for the construction of new enterprises, when new digital equipment of electrical substations is planned for the provision of communication and data transmission channels, as well as for creating automation levels of the enterprise, such as MES, IRP and PLM. For an operating enterprise, consideration of the project for the dispatching of the electricity sector, for example, from Siemens, will require the preparation, specifically replacement of power equipment for substations, which is difficult to justify in the conditions of resources economy within the enterprise.

The analysis of the proposals of domestic producers has led to the possibility of considering more cost-effective solutions in the conditions of real production. In particular, the company "Tavrida electric" offers a compromise option - retrofit program for cells with the replacement of oil switches to high-speed vacuum BB/TEL to provide digital communication channels from the equipment of substations. [14]

The development of an integrated system of management of enterprise's electrical facilities should now take place in stages to come to achieve dispatching control in a hierarchical structure, improving individual subsystems and integrating into the overall system of enterprise dispatching.

\section{Object and methods of research}

Taking into account the successful practices on the implementation of energy management systems, the following areas of improvement of dispatching systems of electrical power facilities at industrial enterprises are possible:

Creation of a modern organizational and technical level of dispatching of the enterprise's electrical facilities with operating control and analysis of work for making management decisions aimed at reducing energy costs while retaining the high quality of products;

- Prevention or reduction of damage from accidents on power grids due to the rapid identification of the places of occurrence and nature of the accident and, consequently, reducing the time for localization and elimination of the emergency situation and its consequences;

- Accumulation of statistically processed data for planning and formation of power consumption modes, development of specific rates of power consumption;

- Smart current electricity consumption and elimination of penalties from the energy supply organization;

- $\quad$ Provision of optimal modes of electro-intensive processes conducting;

- $\quad$ Reduction of time for operational switching in order to reduce unplanned downtime of process equipment;

- Control over the optimal use of process equipment to reduce idle time and unplanned downtime.

The study was conducted at zinc production metallurgical enterprise.

First of all, the analysis of the electric power facilities for 5 years was performed, which showed that: 
- The installed capacity of the enterprise's electric receivers is $57,6 \mathrm{MW}$, including zinc production of 44,6 MW;

- The main consumers of electricity are copper tankhouse $(72,6 \%$ of allconsumption), the sulphuric acid plant $(4,5 \%)$, steam power plant $(4,3 \%)$, roasting plant (by $3,4 \%)$, Waelz-process shop (2,6\%);

- Consumption of other shops is less than $1 \%$ of the total plant consumption.

The total capacity of electric receivers of 1 and 2 categories of reliability is $42 \mathrm{MW}$, which is $68 \%$ of the enterprise capacity.

Therefore, for the stable operation of the enterprise (figure1), it is necessary to provide reliable and safe power supply in accordance with the categorization, and the development of dispatching system of the electric power facilities is considered as a tool for the management of electric power facilities of enterprise.

Despite not a large percentage of electricity consumption of sulfuric acid plant in relation to the total, the study takes into account this unit, significant from the point of view of environmental safety. If the electricity supply of the sulfuric acid plant is disrupted, a huge release of sulfur dioxide into the environment can occur, which will lead to environmental danger not only for production, but also for the city.

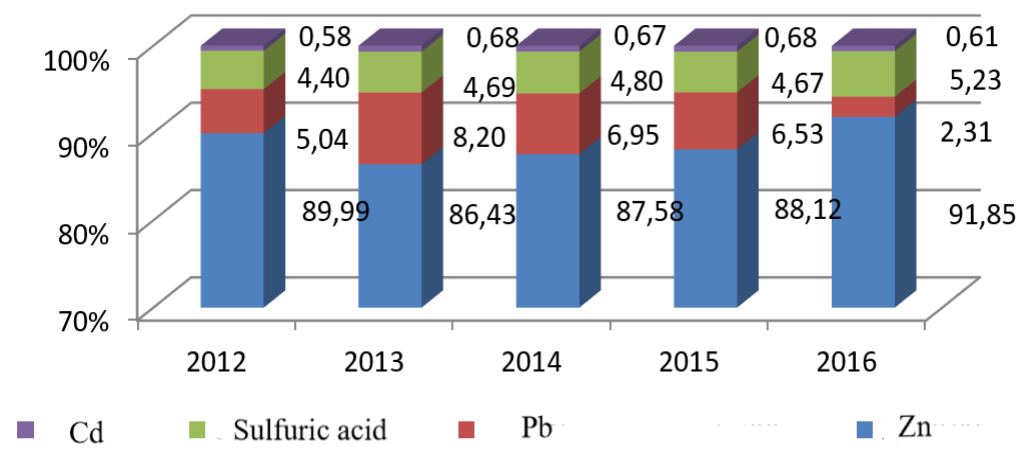

Fig. 1. The structure of the electrical energy consumption by type of product.

The analysis of the structure of the ODE of electrical power facilities of the plant revealed its specific qualities:

- Hierarchical construction of the system with direct subordination of the duty operational personnel of each stage of management to higher-level personnel;

- Presentation to the staff of each level of maximum independence in the performance of all operational functions that do not require the intervention of the operations supervisor of a higher level;

- Clear separation of functions and responsibilities of operational personnel at all stages of management in maintaining normal condition and eliminating emergencies;

- Stringent dispatching discipline.

In addition, defects of ODO electrical facilities were revealed both at the enterprise level and in the sulfuric acid plant, in more detail:

The existing algorithm of information collection is performed during the around check of the on-duty electrician of the electrical equipment of the plant (about 25-30 minutes);

- Insufficient speed of decision-making and actions in accident situations;

- Lack of obtaining the necessary information about the condition of switching devices switchgear - $6 \mathrm{kV}$ and switchgear - 0,4 kV and electric parameters (current, voltage, power) of the main technological equipment of the plant; 
- $\quad$ Lack of an automated workstation (AWS) of the on-duty electrician of the sulfuric acid plant;

- Lack of archive of accident situations necessary for a detailed analysis of the accident situation.

- Downtime analysis of the technological equipment of the enterprise (up to 1,5 hours per year), and, consequently, the underproduction of commodity zinc, proved the need to develop technical and organizational solutions to reduce them.

The pilot project for constructing the dispatch control system (DCS) of the electrical facility was started in the sulfuric acid plant, and the environmental safety of production is depend from its work.

The developed structural diagram of the automated DCS of the electrical facility in the sulfuric acid plant is shown in figure 2 .

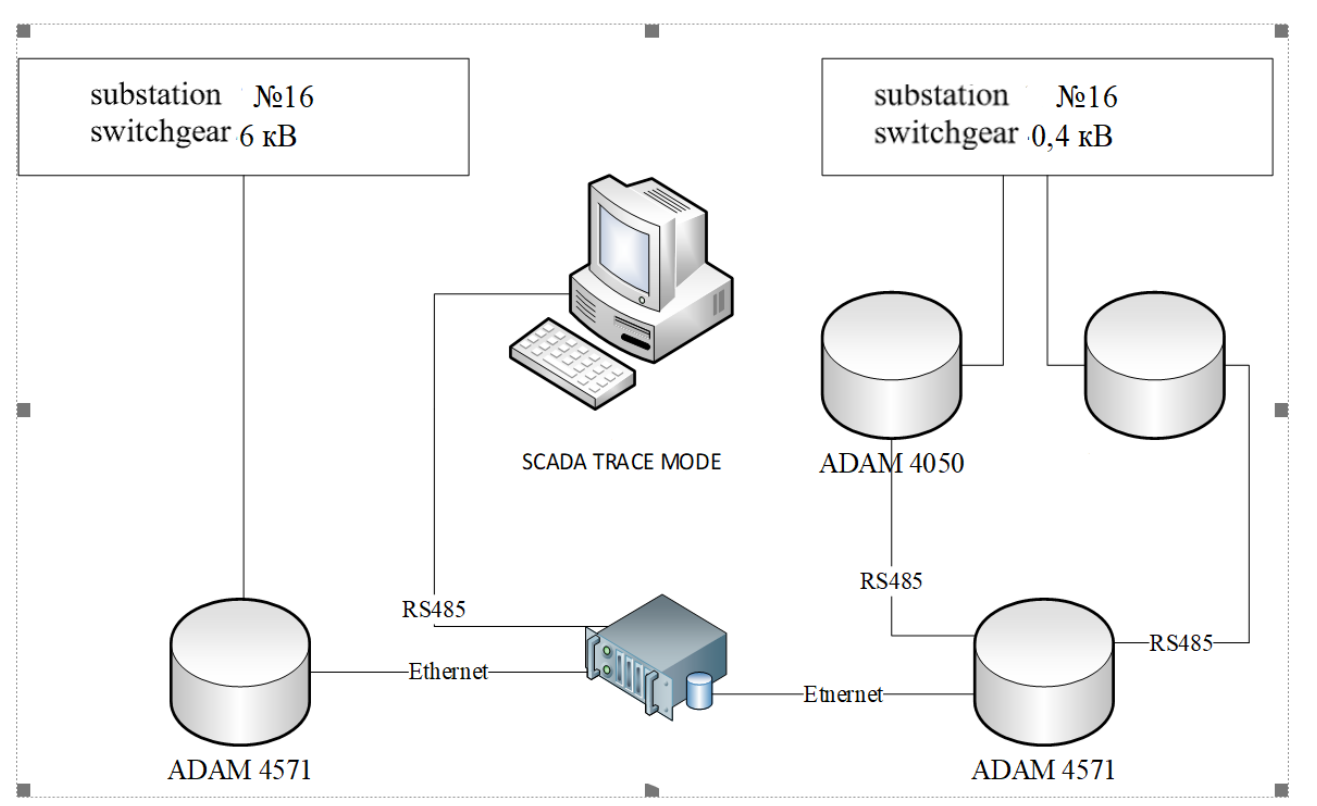

Fig. 2. Structured scheme of data collection for DCS.

DCS unified information channels switchgear $-6 \mathrm{kV}$ and switchgear $-4 \mathrm{kV}$, substation № 16. For this purpose, relay protection was replaced with microprocessor blocks.

It was compiled the list of equipment has a particular impact on the sulfuric acid technology subdivision. This list includes introductory automata, electric motors for pumps and fans, etc.

Then the equipment was selected to output information about the condition of switching devices switchgear - $0,4 \mathrm{kV}$, AWS is organized for duty personnel.

To display information about the position of switching devices, free block contacts and additional block contacts were used to expand the possibility of using contactors in systems of technological processes automation.

To display information on current load, power and voltage overload electric motors relays were used.

In order to deduce the position of the input circuit breakers switchgear $-0,4 \mathrm{kV}$, the free block of contacts were used, and for the output of the information, the network parameters module ME110-220 was used. The module of the electrical network parameters inputting ME110-220.3M is designed for measuring of voltage, current strength, frequency, power, 
phase angle and power factor in three-phase networks, converting the measured parameters into digital code and transferring the measurement results to the RS-485 network.

For the exchange of data between the computer and the ME110-220, the ADAM-4571 interface converter is used. It converts the RS-485 interface (Modbus RTU protocol) to an Ethernet interface (Modbus TCP protocol). ADAM-4571 is a data gateway between RS232/422/485 and Ethernet interfaces.

These SCADA-system receives and processes them, ensuring operation in real-time data collection, processing, displaying and archiving the information of the monitoring or management object. This equipment allows visualization of not only the switching devices position, but also visualization of parameters: current, voltage, load, and collect statistics on emergency shutdowns.

\section{Results}

Implementation of the pilot project in 2017 allowed duty personnel to solve the following tasks:

- $\quad$ Promptly respond to the power consumption modes of the main process equipment of the plant, analyze and make decisions on their optimization;

- $\quad$ Promptly make decisions in emergency and emergency situations;

- To control the condition of switching devices not only switchgear $-6 \mathrm{kV}$, but also switchgear - $0,4 \mathrm{kV}$ via visualization on the mnemonic diagram of AWS;

- To monitor the parameters of the power equipment of the substation;

- $\quad$ To ensure the reliability of power supply and environmental safety of the sulfuric acid plant.

By means of the emergency response training drills, the time for starting the plant from 30 minutes to 8 minutes has been proven when comparing before and after the introduction of DCS.

With the purpose of transition to the enterprise level in the field of building a dispatching system, taking into account the successful practice of the DCS plant, it is necessary to:

- Develop a structural and organizational DCS diagram of the condition of the main step-down substations' switching devices;

- Justify the selection of necessary and sufficient switching devices;

- Carry out the selection of equipment: microprocessor protection blocks, position sensors, a system of data collection and passing units, a fiber-optic communication system, software for visualizing the switching devices position;

- Develop the basic organizational and technical solutions for improving the dispatching system of the enterprise, taking into account the possibility of organizing the level of the MES-system [4].

To create DSC of the company's electrical facilities, information channels were formed that unite the three main step-down substations (MS-DSS), and the necessary equipment was selected. The equipment includes the microprocessor relay protection, position sensors, system of data collection and transmission device, fiber optic communication system, software for the visualization of the switching devices position.

Position sensors - reed switches were used to visualize the position of the disconnectors. Under the influence of force lines, the contacts are magnetized and, upon overcoming the elastic threshold, they commute the circuit.

For data transmission, it was decided to use a fiber-optic communication system. To collect information, the ADAM 4571 controllers was used. The data collection scheme is shown in figure 3. 


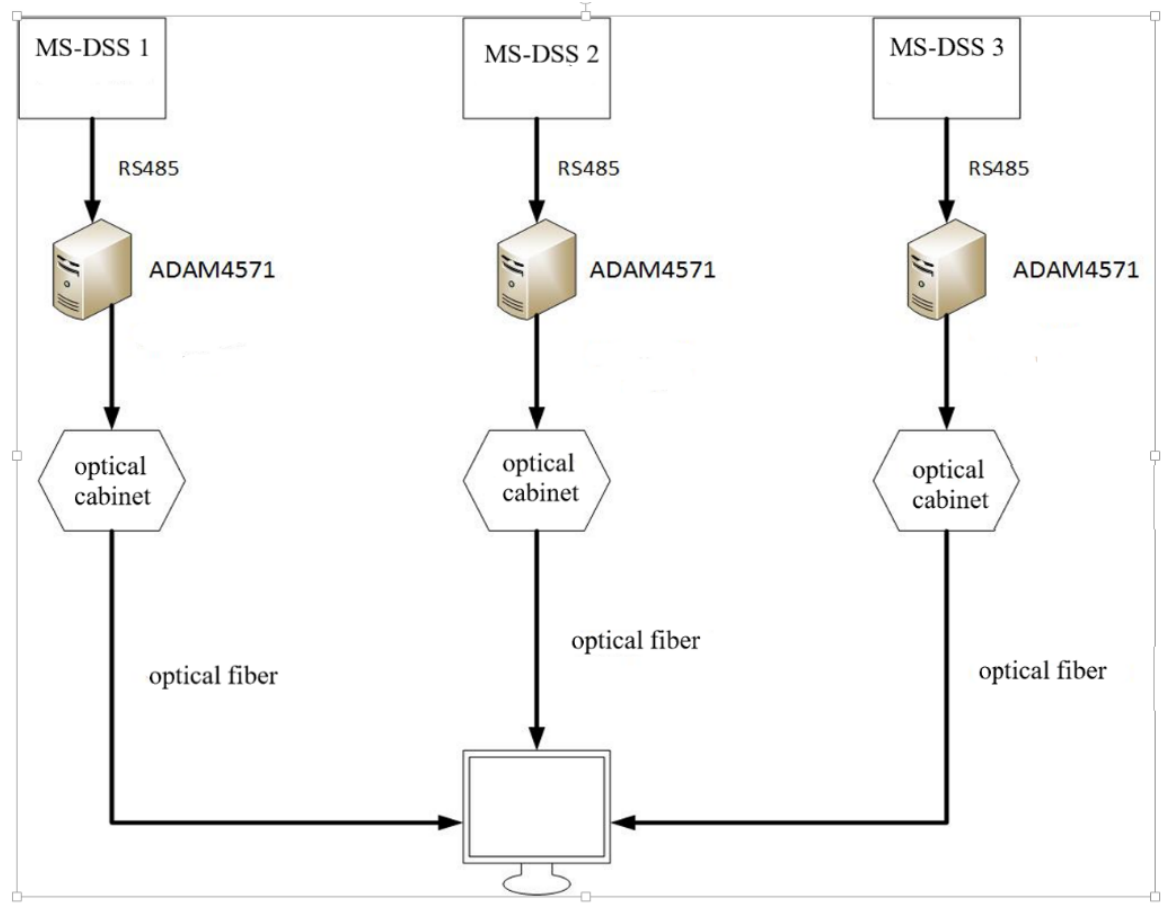

Fig. 3. Automated data acquisition system.

Based on the DCS AWP at the enterprise level, we developed elements of system for the substation equipment state assessing using the indicative method. $[15,16]$

The essence of method is that the evaluation of the equipment operation of the power supply system requires a strict classification of the states with a breakdown by the degree of accident rate for each indicator, the indicative block and the generalized state in general. [17]

State analysis is performed by comparing an indicator or a group of indicators with the corresponding threshold values. To assess the operability, the following states can be entered: normal, pre-emergency, emergency. Generalized assessment of the substation equipment state is formed on the basis of indicators for indicative blocks.

To determine the threshold levels for indicative indicators in the formation of the evaluation system, the expert method is used, and various scales can be used (normal, Saati, etc.).

We have formed three indicative blocks, namely:

- The operating unit characterizes the state of the equipment according to performance indicators. In our design, the system will keep track of the clock developments of vacuum switches according to the nameplate data for the timely conduct inter-service repairs (technical inspection, maintenance, and overhaul).

- Electric energy quality assessment block. The given block will allow to carry out an estimation on indicators of electric energy quality on borders of a balance accessory according to GOST 32144-2013.

- The environmental block determines the degree of facilities and the power supply system impact as a whole on the ecological situation. This unit monitors idle time, i.e. absence of voltage on the feeder E216 and E221, which provide sulfuric acid subdivision electricity.

The method of indicative analysis allows assessing of the power equipment status in the power supply system of the enterprise. 
Availability of historical information about the status of the equipment will determine its future state, extrapolating past experience.

The developed system of dispatching the electrical facilities at the enterprise level will allow to solve the following tasks of control and registration:

- $\quad$ To provide control of the condition of the substations' main equipment;

- Registration of parameters necessary for the operational analysis of electrical equipment, personnel and automation equipment;

- Registration of accident situations and documentation of actions of substation systems and personnel in pre-accident and accident situations, as well as during the liquidation of accidents;

Control of the operations on the commissioning and withdrawal of the main equipment for the repair and preparation of workplaces for repair teams.

In addition, the design system will provide the solution of tasks for managing the equipment of the substations of the enterprise:

- $\quad$ Auto-Transfer System;

- Management of the set of working transformers, load in heavy and emergency conditions;

- Remote control of switching equipment, activation of the setting of protective relays and automation program (PRAP).

\section{Conclusions}

The integration of data from the automated process control system, automatic system for commercial measurement of power consumption, automated system of electric power technical metering into the proposed DCS of the electric facility, makes it possible to control the specific consumption of electricity by significant technological equipment, and also to construct efficient methods for planning electricity when operating on the wholesale market, i.e. to build a system for managing the enterprise electrical equipment.

\section{References}

1. G.V. Nikiforov, V.K. Oleinikov, B.I. Zaslavets, A.N. Shemetov, Electrical equipment: operation and maintenance 2, 12-21 (2014)

2. S.V. Fedorova, A.N. Shemetov, R.N. Lyapin, S.V. Kuznetsov, Journal of Electrotechnical Systems and Complexes 4(33), 41-48 (2016)

3. L.A. Koptsev, Industrial Energy 11, 14-21 (2011)

4. L.S. Kazarinov, T.A. Barbasova, A.A. Zakharova, Bulletin of the South-Ural State University, Series "Computer Technology, Control, Electronics" 23, 118-122 (2012)

5. V.A. Ivashchenko, D.A. Vasiliev, Yu.I. Martynov, A.F. Reznikov, Problems and Prospects of Precision Mechanics and Control in Mechanical Engineering: Materials of Intern. Conf., IPTMU RAS, 87-97 (2006)

6. P.Y. Khudyakov, A.Y. Kiselnikov, A.V. Burkov, 6th Intern. Scientific-practical. Conf. in the framework of a specialist. forum "Expo Build Russia» (Publishing house TC UPI, Yekaterinburg, 2017)

7. N.P. Scriabin, N.D. Pozdeev, A.N. Alyunov, Operative management of distribution Electric networks. Textbook (VSTU, Vologda, 2011)

8. V.A. Semenov, Fundamentals of operational dispatch control of power systems (STF "Energy progress", Moscow, 2003) 
9. The system of operational dispatch control in the electric power industry, index.php?id=ees

10. Yu.N. Rudenko, V.A. Semenov, Automation of dispatching management in electric power industry (Publishing house MEI, Moscow, 2000)

11. URL: http://www.omep.ru/services/automanage/automatization/DesigoProjects.pdf

12. URL: https://www.schneider-electric.ru/

13. URL: https://new.abb.com/ru/

14. URL: https://www.tavrida.com/ter/solutions/

15. O.B. Moshinsky, Development of a model for functional state assessing of the electricity supply system in megacities (Abstract, Ekaterinburg, 2011)

16. I.E. Gagloev, Management of electric power facilities on the basis of their condition assessment (Chief Power Engineer, 2016)

17. A.I. Halismaa, S.A. Dmitriev, S.E. Kokin, Industrial power 2, 36-40 (2014) 